\title{
TRIGO, TRITICALE E CENTEIO: AVALIAÇÃO DA EFICIÉNCIA AO FÓSFORO E TOLERÂNCIA À TOXICIDADE AO ALUMÍNIO (1)
}

\author{
CARLOS EDUARDO DE OLIVEIRA CAMARGO $\left({ }^{2,3}\right)$ e JOÄO CARLOS FELICIO $(2,3)$
}

\begin{abstract}
RESUMO
Com o objetivo de estudar a eficiência da utilizaçāo de fósforo e a tolerância à toxicidade ao alumínio, instaiou-se um experimento empregando os cultivares de trigo $\mathrm{BH}-1146$, Anahuac, IAC-5, IAC-24 e IAC-21; 0 de triticale TCEP 77138 e o de centeio Branco, em soluções nutritivas contendo cinco níveis de fósforo $(0 ; 3,1 ; 6,2 ; 12,4$ e $31 \mathrm{mg} /$ litro) combinados com cinco niveis de alumínio $(0,1,3,6$ e $10 \mathrm{mg} /$ /itro). A eficiência ao fósforo foi avaliada levando-se em consideração a produção de matéria seca e a quantidade de $P$ nela presente, e a tolerância ao alumínio, com base no comprimento máximo das raízes após doze dias de crescimento em soluções nutritivas. O cultivar de centeio e o de triticale mostraram maior tolerância ao alumínio. Os cultivares de trigo $\mathrm{BH}-1146$, IAC-21, IAC-5 e IAC-24 apresentaram-se como tolerantes eAnahuac, como sensivel. $O$ sintoma da toxicidade de aluminio ficou acentuado pelo aumento das concentrações de aluminio e fósforo para todos esses cultivares. 'IAC-5' foi considerado eficiente na utilização de fósforo; 'IAC-21' e 'IAC-24', moderadamente eficientes, e 'Anahuac', Ineficiente, em soluções contendo baixos niveis de fósforo na presença de $\mathrm{Al}^{3+}$.
\end{abstract}

Termos de indexação: trigo, triticale, centeio, cultivares; tolerância ao aluminio, eficiência ao fósforo, comprimento da raiz, peso seco da parte aérea, soluçāo nutritiva.

( ${ }^{1}$ ) Com recursos complementares do Acordo do Trigo entre as Cooperativas de Produtores Rurais do Vale do Paranapanema e a Secretaria da Agricultura, por meio do Instituto Agronômico. Apresentado na XIV Reuniäo Nacional de Pesquisa de Trigo, Londrina (PR), julho de 1986. Recebido para publicaçāo em 28 de julho de 1988. $\operatorname{nas}(\mathrm{SP})$.

(2) Seção de Arroz e Cereais de Inverno, Instituto Agronômico (IAC), Caixa Postal 28, 13001 Campi-

(3) Com bolsa de pesquisa do CNPq. 


\section{INTRODUÇÃO}

A triticultura brasileira, em sua grande parte, instala-se em solos ácidos, com elevados teores de alumínio trocável ou solúvel e baixa disponibilidade de fósforo, apresentando, nessas condições, baixa produtividade.

O alumínio no solo ácido paralisa a divisão celular no meristema apical das raízes, resultando em drástica redução no sistema radicular (MOORE et al., 1976). Essa característica tem sido usada como um critério para a toxicidade de alumínio, e a resposta diferencial das raízes, para avaliar a variação genética na tolerância ao alumínio (ALI, 1973, e FOY et al., 1974).

$\mathrm{O}$ ' $\mathrm{BH}-1146$ ' mostrou produção significativamente superior aos cultivares Tobari-66, Alondra-S-46, IAC-17 e Siete Cerros em solo ácido sem calcário, confirmando a sua tolerância ao alumínio, em soluçāo nutritiva. A tolerância à toxicidade de alumínio é um fator importante para garantir bom desenvolvimento do sistema radicular do trigo: permite a obtenção de água em maior profundidade em condições de seca, onde o cultivar suscetivel não sobreviveria, dada a inibição pelo alumínio do crescimento do sistema radicular além da camada superficial do solo, a qual em geral é corrigida (CAMARGO \& OLIVEIRA, 1981).

A toxicidade de alumínio não é o único fator limitante em solos ácidos; portanto, os métodos de separação de plantas tolerantes e suscetíveis a determinado nivel de alumínio usando solos ácidos não são bastante precisos. Além disso, as partes da planta diretamente afetadas, as raízes, não são facilmente observadas. $O$ emprego de soluções nutritivas pode tornar mais eficiente e precisa a separação das plantas em relação à tolerância ao alumínio (CAMPBELL \& LAFEVER, 1976).

Foi demonstrado em soluções nutritivas que os cultivares de triticale foram mais tolerantes que os de trigo, a $5 \mathrm{mg} / \mathrm{litro}$ de $\mathrm{Al}^{3+}$. Todos eles foram sensiveis a $10 \mathrm{mg}$ por litro de $\mathrm{Al}^{3+} \mathrm{e}$ os dois de centeio, Goyarowo e Branco, tolerantes a $20 \mathrm{mg}$ por litro de $\mathrm{Al}^{3+}$ (CAMARGO \& FELICIO, 1984).

GABELMAN, 1976, GERLOFF, 1976, e WHITEAKER et al., 1976, estudando 54 cultivares de feijão em soluções nutritivas contendo 2 ppm de $P$ por planta, separaram os cultivares nas seguintes classes: eficientes, moderadamente eficientes e ineficientes, com base no peso seco da parte aérea e na proporção da eficiência do emprego de fósforo ( $P E R$ ), definida como miligrama de matéria seca produzida por miligrama de $\mathrm{P}$ no tecido. Esses autores também verificaram, estudando os mesmos cultivares em soluções contendo 31 e $62 \mathrm{mg}$ de $P$ por planta, que alguns deles apresentavam aumento de crescimento quando o $\mathrm{P}$ da solução aumentava para os niveis mais elevados, enquanto outras iinhagens não mostravam resposta.

Os cultivares de trigo IAC-5, IAS-20, BH-1146 e IAC-17 foram considerados eficientes na utilizaçāo de fósforo; $|A C-18| A C-$,13 e IAC-15, moderadamente eficientes, e Siete Cerros, INIA-66 e Alondra-S-46, ineficientes, levando-se em 
consideração a produção de matéria seca da parte aérea e a proporção entre a produção de matéria seca da parte aérea e a quantidade de $P$ nela presente para as soluçōes contendo $3,875 \mathrm{mg} /$ /itro de $\mathrm{P}$ (CAMARGO, 1984). O 'IAC-5', eficiente na utilização e absorção de fósforo em baixas concentrações desse elemento na solução nutritiva e no solo, poderia ser cultivado em solos com baixa disponibilidade de fósforo: à medida que a concentração desse elemento aumentasse por práticas de adubação fosfatada, o cultivar responderia elevando a produtividade.

O presente trabalho teve por objetivo estudar o comportamento de cultivares de trigo, triticale e centeio em relação à eficiência à utilização de fósforo e à tolerância à toxicidade de alumínio em solução nutritiva.

\section{MATERIAL E MÉTODOS}

Estudaram-se os cultivares de trigo $\mathrm{BH}-1146$, Anahuac, IAC-5, IAC-21 e IAC-24; o de centeio Branco e o de triticale TCEP 77138, em soluçōes nutritivas contendo cinco niveis de alumínio combinados com cinco níveis de fósforo.

Colocaram-se as sementes desses cultivares, cuidadosamente lavadas com uma soluçăo de hipoclorito de sódio a 10\%, para germinar em caixas de Petri por 24 horas. Após esse tempo, as radículas estavam iniciando a emergência.

Escolheram-se 15 sementes uniformes de cada cultivar, colocando-as sobre a superfície de 25 telas de náilon, que foram adaptadas sobre 25 vasilhas plásticas de 8,3 litros de capacidade com soluções nutritivas contendo um décimo da concentração da solução nutritiva completa com $0,1,3,6$ e $10 \mathrm{mg}$ por litro de $\mathrm{Al}^{3+}$ combinados com $0 ; 3,1 ; 6,2 ; 12,4$ e $31 \mathrm{mg}$ por litro de fósforo.

Como controle, escolheram-se 10 e 15 sementes de cada cultivar, pondo-as sobre o topo de duas telas de náilon: uma delas, em contacto com solução nutritiva completa $\mathrm{e}$, a outra, com água destilada, existentes em vasilhas plásticas de 8,3 litros de capacidade.

A composição da soluçāo nutritiva completa utilizada foi a seguinte: $\mathrm{Ca}\left(\mathrm{NO}_{3}\right)_{2} \quad 4 \mathrm{mM} ; \quad \mathrm{MgSO}_{4} \quad 2 \mathrm{mM} ; \mathrm{KNO}_{3} \quad 4 \mathrm{mM} ; \quad\left(\mathrm{NH}_{4}\right)_{2} \mathrm{SO}_{4} \quad 0,435 \mathrm{mM}$; $\mathrm{KH}_{2} \mathrm{PO}_{4} \quad 0,5 \mathrm{mM} ; \quad \mathrm{MnSO}_{4} \quad 2 \mu \mathrm{M} ; \mathrm{CuSO}_{4} \quad 0,3 \mu \mathrm{M} ; \mathrm{ZnSO}_{4} \quad 0,8 \mathrm{iM} ; \mathrm{NaCl} 30 \mu \mathrm{M}$;

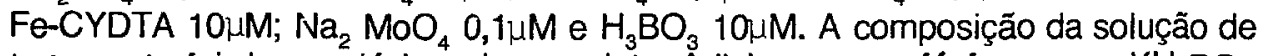
tratamento foi de um décimo da completa. Ádicionou-se o fósforo como $\mathrm{KH}_{2} \mathrm{PO}_{4}$, de modo a obter soluçōes tratamentos com $0 ; 3,1 ; 6,2 ; 12,4$ e $31 \mathrm{mg} /$ /litro de fósforo, $e$, o ferro, em quantidade equivalente à da solução completa como $\mathrm{FeCl}_{3}$ no lugar de Fe-CYDTA. Antes de pôr as sementes sobre as telas, adicionou-se suficiente $\mathrm{H}_{2} \mathrm{SO}_{4} 1 \mathrm{~N}$ nas soluçôes de tratamento, para trazer o $\mathrm{pH}$ para cerca de 4,2 e a necessária quantidade de alumínio como $\mathrm{Al}_{2}\left(\mathrm{SO}_{4}\right)_{3} \cdot 18 \mathrm{H}_{2} \mathrm{O} . \mathrm{O} \mathrm{pH}$ final foi ajustado para 4,0 com uma solução de $\mathrm{H}_{2} \mathrm{SO}_{4} 1 \mathrm{~N}$, evitando-se adicionar $\mathrm{NaOH}$, que poderia causar a precipitação do alumínio, pelo menos no local de queda da gota. 
As soluções foram continuamente arejadas, ficando as vasilhas plásticas em banho-maria a $25 \pm 1^{\circ} \mathrm{C}$. Durante todo o experimento, que foi mantido com luz fluorescente em sua totalidade, $\mathrm{opH}$ das soluçōes foi conservado o mais próximo possivel de 4,0, com ajustamentos diários.

As plantas desenvolveram-se nas diferentes soluções de tratamento por doze dias. Decorrido esse período, foram retiradas das soluções, determinando-se - crescimento máximo da raiz primária central de cada plântula, em milímetro.

O delineamento estatístico empregado foi de blocos ao acaso com parcelas subdivididas com duas repetições: as parcelas foram compostas pelas cinco concentraçōes de fósforo combinadas com as cinco concentrações de alumínio e, as subparcelas, pelos diferentes cultivares de trigo, centeio e triticale. Analisaram-se os dados, considerando-se a média do crescimento máximo da raiz primária central das 15 e 10 plântulas de cada cultivar, respectivamente, na prımeıra e na segunda repetição. A comparação entre as médias de crescimento máximo da raiz dos cultivares submetidos a uma mesma concentração de alumínio, independente do nível de fósforo utilizado, foi feita pelo teste de Tukey.

Separaram-se as raízes das partes aéreas de cada cultivar submetido a crescimento nas soluções com $0 \mathrm{mg}$ por litro de $\mathrm{Al}^{3+}$ e $3 \mathrm{mg}$ por litro de $\mathrm{Al}^{3+}$, combinadas com cinco concentrações de fósforo. Juntaram-se as partes aéreas das duas repetiçōes, colocando-as para secar em estufa, a $70^{\circ} \mathrm{C}$, por cinco dias, determinando-se então os respectivos pesos secos em miligrama. As folhas (parte aérea) dos cultivares Anahuac, IAC-5, IAC-21 e IAC-24 foram analisadas quimicamente quanto ao teor de $P$, segundo o método de BATAGLIA et al. (1978).

Para expressar a eficiência do uso de fósforo de cada um desses cultivares submetidos a crescimento em soluçôes nutritivas contendo diferentes concentrações desse elemento na presença e na ausência de $\mathrm{Al}^{3+}$, adotou-se o critério citado por WHITEAKER et al. (1976): a proporção da eficiência da utilização de fósforo (PER), portanto, foi calculada pela divisão entre o peso seco da parte aérea em miligrama e a quantidade em miligrama de $P$ presente nesses tecidos.

\section{RESULTADOS E DISCUSSĀO}

O comprimento médio das raízes e o peso seco de 25 plântulas de cinco cultivares de trigo, um de triticale e um de centeio, medido após doze dias de crescimento em solução nutritiva completa e em água destilada na ausência de nutrientes, encontram-se no quadro 1.

Pelo teste de Tukey ao nível de $5 \%$ para a comparação dos diferentes cultivares que cresceram doze dias em soluçōes nutritivas completas, 'BH-1146' mostrou as raizes mais compridas, não diferindo, porém, do 'IAC-5' e 'IAC-21'. Quando se empregou água destilada, o 'BH-1146' também apresentou as raizes mais compridas, diferindo, ao nivel de $5 \%$, pelo teste de Tukey, do 'Anahuac' e 
dos cultivares de centeio e triticale. Essas observaçōes confirmaram resultados anteriores. CAMARGO \& OLIVEIRA (1981) e CAMARGO \& FREITAS (1985) mostraram que, em uma solução com $\mathrm{pH}=4,0$, na ausência de niveis tóxicos de ferro e alumínio, o 'BH-1146' apresentou o seu potencial genético no crescimento rápido das raizes, condição essa especifica de cada genótipo.

O comprimento médio das raizes de cinco cultivares de trigo, um de triticale e um de centeio, medido após doze dias de crescimento em soluções nutritivas contendo cinco niveis de fósforo combinados com cinco niveis de alumínio, encontram-se no quadro 2. Pela análise estatística desse experimento, pelo teste $F$, houve efeitos altamente significativos de concentrações de alumínio, cultivares e interações concentrações de $A l x$ concentrações de $P$, cultivares $x$ concentraçōes de $P$, cultivares $x$ concentrações de $A$ l e cultivares $x$ concentrações de $P x$ $x$ concentrações de Al. Não se verificou efeito significativo de concentrações de $P$.

Considerando as médias dos diferentes cultivares estudados em soluçōes contendo $0 \mathrm{mg} /$ /itro de $\mathrm{Al}^{3+}$, independente das concentraçōes de $\mathrm{P}$ utilizadas, não houve diferenças significativas, levando em consideração o comprimento médio das raízes.

QUADRO 1. Comprimento médio das raízes e peso seco da parte aérea de 25 plântulas de cinco cultivares de trigo, um de triticale e um de centeio, medido após 12 dias de crescimento em solução nutritiva completa e em água destilada na ausência de nutrientes

\begin{tabular}{lccccc}
\hline \multirow{2}{*}{ Cultivares } & \multicolumn{2}{c}{ Solução nutritiva completa } & & \multicolumn{2}{c}{ Água destilada } \\
\cline { 2 - 3 } & $\mathrm{c} \begin{array}{c}\text { Comprimento } \\
\text { da raiz }\end{array}$ & Parte aérea & & $\begin{array}{c}\text { Comprimento } \\
\text { da raiz }\end{array}$ & Parte aérea \\
\hline BH-1146 & 247,7 & $\mathrm{mg}$ & $\mathrm{mm}$ & $\mathrm{mg}$ \\
Anahuac & 166,0 & 750 & 30,6 & 464 \\
IAC-5 & 211,8 & 430 & 17,5 & 301 \\
IAC-21 & 227,3 & 750 & 22,6 & 388 \\
IAC-24 & 171,3 & 683 & 24,7 & 400 \\
TCEP 77138 & 157,7 & 449 & 21,4 & 303 \\
Branco & 159,7 & 500 & 16,7 & 299 \\
\hline D.M.S.( $\left.{ }^{1}\right)$ & 62,1 & 369 & 17,6 & 229 \\
\hline
\end{tabular}

(1) Diferenças mínimas significativas ao nivel de $5 \%$ para a comparação das médias de comprimento das raizes dos cultivares de trigo. 
QUADRO 2. Comprimento médio das raizes de cinco cultivares de trigo, um de triticale e um de centeio, medido após 12 dias de crescimento em soluções nutritivas com um décimo da concentração salina da solução completa contendo cinco níveis de fósforo combinados com cinco niveis de aluminio

\begin{tabular}{|c|c|c|c|c|c|c|c|c|c|c|c|}
\hline \multirow{3}{*}{ Cultivares } & \multirow{3}{*}{$\begin{array}{c}\begin{array}{c}\text { Concentraçāo } \\
\text { de fósforo }\end{array} \\
\text { mg/l }\end{array}$} & \multicolumn{10}{|c|}{ Concentração de $\mathrm{Al}^{3+}(\mathrm{mg} / \mathrm{l})$} \\
\hline & & \multicolumn{2}{|c|}{0} & \multicolumn{2}{|c|}{1} & \multicolumn{2}{|c|}{3} & \multicolumn{2}{|l|}{6} & \multicolumn{2}{|c|}{10} \\
\hline & & $\mathrm{mm}$ & $\%$ & $\mathrm{~mm}$ & $\%$ & $\mathrm{~mm}$ & $\%$ & $\mathrm{~mm}$ & $\%$ & $\mathrm{~mm}$ & $\%$ \\
\hline \multirow[t]{5}{*}{$\mathrm{BH}-1146$} & 0 & 155,9 & 100 & 126,5 & 81 & 97,3 & 62 & 46,8 & 30 & 29,6 & 19 \\
\hline & 3,1 & 170,1 & 100 & 105,3 & 62 & 112,8 & 66 & 45,6 & 27 & 25,5 & 15 \\
\hline & 6,2 & 169,3 & 100 & 120,8 & 71 & 117,2 & 69 & 51,2 & 30 & 28,3 & 17 \\
\hline & 12,4 & 149,5 & 100 & $\therefore 63,8$ & 110 & 108,0 & 72 & 28,3 & 19 & 13,8 & 09 \\
\hline & 31,0 & 166,8 & 100 & 209,4 & 126 & 106,8 & 64 & 10,5 & 06 & 13,8 & 08 \\
\hline \multirow[t]{5}{*}{ Anahuac } & 0 & 114,8 & 100 & 12,7 & 11 & 9,9 & 09 & 11,8 & 10 & 8,8 & 08 \\
\hline & 3,1 & 158,2 & 100 & 10,7 & 07 & 13,3 & 08 & 13,1 & 08 & 8,6 & 05 \\
\hline & 6,2 & 158,1 & 100 & 20,6 & 13 & 12,8 & 08 & 9,7 & 06 & 7,4 & 05 \\
\hline & 12,4 & 155,6 & 100 & 53,0 & 34 & 11,1 & 07 & 8,9 & 06 & 9,5 & 06 \\
\hline & 31,0 & 136,6 & 100 & 87,3 & 64 & 13,5 & 10 & 9,2 & 07 & 6,1 & 04 \\
\hline \multirow[t]{5}{*}{$\mid A C-5$} & 0 & 141,2 & 100 & 139,3 & 99 & 70,2 & 50 & 37,6 & 27 & 24,4 & 17 \\
\hline & 3,1 & 166,9 & 100 & 103,9 & 62 & 101,1 & 61 & 34,3 & 21 & 16,3 & 10 \\
\hline & 6,2 & 159,8 & 100 & 95,3 & 60 & 91,3 & 57 & 41,9 & 26 & 24,2 & 15 \\
\hline & 12,4 & 133,5 & 100 & 132,2 & 99 & 107,6 & 81 & 20,6 & 15 & 17,2 & 13 \\
\hline & 31,0 & 143,6 & 100 & 140,2 & 98 & 94,9 & 66 & 14,4 & 10 & 15,4 & 11 \\
\hline \multirow[t]{5}{*}{ IAC-24 } & 0 & 101,5 & 100 & 89,5 & 88 & 73,6 & 73 & 39,6 & 39 & 16,9 & 17 \\
\hline & 3,1 & 113,6 & 100 & 75,3 & 66 & 78,8 & 69 & 39,5 & 35 & 27,6 & 24 \\
\hline & 6,2 & 121,2 & 100 & 90,6 & 75 & 78,9 & 65 & 45,4 & 37 & 19,7 & 16 \\
\hline & 12,4 & 116,7 & 100 & 80,6 & 69 & 89,1 & 76 & 28,0 & 24 & 12,9 & 11 \\
\hline & 31,0 & 113,7 & 100 & 105,2 & 93 & 74,8 & 66 & 17,1 & 15 & 11,6 & 10 \\
\hline \multirow[t]{5}{*}{ IAC-21 } & 0 & 117,0 & 100 & 133,9 & 114 & 85,9 & 73 & 34,7 & 30 & 23,0 & 20 \\
\hline & 3,1 & 149,4 & 100 & 106,7 & 71 & 89,3 & 60 & 34,9 & 23 & 20,7 & 14 \\
\hline & 6,2 & 144,5 & 100 & 106,1 & 73 & 87,3 & 60 & 49,7 & 34 & 23,4 & 16 \\
\hline & 12,4 & 136,0 & 100 & 132,8 & 98 & 94,6 & 70 & 28,5 & 21 & 14,5 & 11 \\
\hline & 31,0 & 125,5 & 100 & 172,8 & 138 & 85,4 & 68 & 16,4 & 13 & 13,4 & 11 \\
\hline \multirow[t]{5}{*}{ TCEP 77138} & 0 & 123,1 & 100 & 115,7 & 94 & 113,3 & 92 & 63,5 & 52 & 53,8 & 44 \\
\hline & 3,1 & 124,4 & 100 & 111,8 & 90 & 121,5 & 98 & 60,9 & 49 & 53,7 & 43 \\
\hline & 6,2 & 137,8 & 100 & 140,6 & 102 & 128,8 & 93 & 56,3 & 41 & 46,9 & 34 \\
\hline & 12,4 & 124,9 & 100 & 135,0 & 108 & 125,3 & 100 & 28,2 & 23 & 33,4 & 28 \\
\hline & 31,0 & 106,7 & 100 & 119,2 & 112 & 104,3 & 98 & 18,7 & 18 & 8,3 & 08 \\
\hline \multirow[t]{5}{*}{ Branco } & 0 & 110,2 & 100 & 141,1 & 128 & 119,4 & 108 & 49,5 & 45 & 55,2 & 50 \\
\hline & 3,1 & 106,1 & 100 & 118,1 & 111 & 106,3 & 100 & 59,5 & 56 & 53,0 & 50 \\
\hline & 6,2 & 109,1 & 100 & 139,5 & 128 & 89,8 & 82 & 77,8 & 71 & 53,2 & 49 \\
\hline & 12,4 & 110,9 & 100 & 161,8 & 146 & 138,7 & 125 & 31,4 & 28 & 52,3 & 47 \\
\hline & 31,0 & 95,9 & 100 & 96,9 & 101 & 150,9 & 157 & 45,3 & 47 & 23,9 & 25 \\
\hline D.M.S. $\left(^{1}\right)$ & & 62,1 & & 36,0 & & 31,5 & & 13,5 & & 12,2 & \\
\hline
\end{tabular}

(1) Diferenças mínimas significativas ao nivel de $5 \%$ para a comparação das médias dos cultivares dentro de uma mesma concentração de alumínio, independente do nivel de fósforo utilizado. 
Considerando $1 \mathrm{mg} /$ litro de $\mathrm{Al}^{3+}$, todos os cultivares apresentaram uma tendência de aumentar 0 crescimento das raízes à medida que se elevaram as concentraçōes de $P$ nas soluçōes. As diferenças no crescimento das raízes na presença de 0 e $31 \mathrm{mg}$ por litro de $\mathrm{P}$ somente foram significativas para os cultivares $\mathrm{BH}-1146$ e Anahuac. Este foi o mais sensivel com a adição de $1 \mathrm{mg}$ por litro de $\mathrm{Al}^{3+}$ nas soluções de tratamento, diferindo estatisticamente dos demais quando se utilizaram as concentrações de 0; 3,1 e 6,2 mg/ilitro de P. Com a adição de $31 \mathrm{mg}$ por litro de P, o 'Anahuac' recuperou em parte o crescimento de suas raízes, diferindo significativamente somente dos cultivares mais tolerantes a $1 \mathrm{mg} / \mathrm{litro}$ de Al: BH-1146, IAC-5 e IAC-21.

Nas soluções contendo $3 \mathrm{mg} /$ !itro de $\mathrm{Al}^{3+}$, não houve efeito significativo da elevação da concentração de $P$ no crescimento das raizes, com exceção do cultivar de centeio, que apresentou um crescimento significativo quando a concentração de $P$ aumentou de 3,1 para 31,0 mg/litro. 'Anahuac' foi o mais sensivel a essa concentração de Al, diferindo de todos os outros. O 'Branco' foi o mais tolerante a $3 \mathrm{mg} / \mathrm{htro}$ de $\mathrm{Al}^{3+}$, diferindo significativamente dos demais com a adição de $31,0 \mathrm{mg} / \mathrm{litro}$ de $P$.

Quando se adicionaram $6 \mathrm{mg} / \mathrm{litro}$ de $\mathrm{Al}^{3+}$, verificou-se, para todos os cultivares, à exceção do Anahuac, um decréscimo significativo no crescimento das raízes à medida que se elevou a concentração de fósforo de 0 para 31,0 $\mathrm{mg} /$ litro nas soluções. O. 'TCEP 77138 ' foi o mais tolerante a $6 \mathrm{mg} / \mathrm{itro}$ de $\mathrm{Al}^{3+}$ quando não se adicionou $P$, apresentando as raizes mais compridas, diferindo pelo teste de Tukey a $5 \%$ dos demais cultivares, porém não diferindo do centeio 'Branco' quando se adicionaram 3,1 mg/litro de $P$ nas soluções; apresentou,todavia,um crescimento radicular significativamente superior ao dos demais. $O$ 'Branco' diferiu dos demais quando se colocaram $6,2 \mathrm{mg} / \mathrm{litro}$ de $\mathrm{P}$ nas soluções, sendo, nessas condiçōes, o mais tolerante a $6 \mathrm{mg} /$ /ittro de $\mathrm{Al}^{3+}$. Esses resultados estão de acordo com os obtidos por CAMARGO \& FELÍCIO (1984): os cultivares de centeio estudados foram mais tolerantes à toxicidade de $\mathrm{Al}^{3+}$ do que os de triticale e, estes, mais tolerantes aos de trigo. O centeio 'Branco' somente diferiu de 'Anahuac' com a adição de $12,4 \mathrm{mg} /$ litro de $P$ na solução, porém apresentou o maior crescimento das raízes na presença de $31,0 \mathrm{mg} /$ /itro de $P$, diferindo dos demais e confirmando a sua maior tolerância a $6 \mathrm{mg} / \mathrm{litro}$ de $\mathrm{Al}^{3+}$.

Considerando as soluções que receberam $10 \mathrm{mg} /$ litro de $\mathrm{Al}^{3+}$, verifica-se que, com exceção dos cultivares Anahuac e IAC-24, sensíveis a essa concentração de $\mathrm{Al}^{3+}$, os demais apresentaram uma redução estatisticamente significativa à medida que se elevou a concentração de fósforo da solução de 0 para 31,0 $\mathrm{mg} /$ /itro. Nas soluções com $0 ; 3,1$ e $6,2 \mathrm{mg} /$ /itro de $P$, os cultivares de centeio e triticale apresentaram as raizes mais compridas, diferindo estatisticamente dos de trigo. ' $\mathrm{BH}-1146$ ' foi o cultivar de trigo que apresentou o maior crescimento radicular na presença de $10 \mathrm{mg} / \mathrm{litro}$ de $\mathrm{Al}^{3+}$ e na ausência de $\mathrm{P}$, diferindo, porém, do 
'IAC-24 e 'Anahuac'. Quando se empregaram soluções com 12,4 mg/litro de P, o cultivar de centeio foi o mais tolerante, diferindo dos demais. Com $31 \mathrm{mg} /$ litro de $P$, ele exibiu pequeno crescimento das raízes, porém ainda diferiu dos cultivares Anahuac, IAC-24 e TCEP 77138.

Pelos resultados obtidos, ficou demonstrado que o sintoma da toxicidade de $\mathrm{Al}^{3+}$ - redução do comprimento das raízes - ficou acentuado pelo aumento da concentração de alumínio e de fósforo nas soluçōes para todos os cultivares estudados. Eles estão de acordo com os obtidos por CAMARGO (1985); à medida que cresceram as concentrações de $\mathrm{P}$ das soluções, os teores de Al aumentaram nas raízes para todos os cultivares em estudo, evidenciando que, com o aumento da concentração de $\mathrm{P}$, acentuou-se $o$ efeito da toxicidade de $\mathrm{Al}^{3+}$, indicando que o Al e o $\mathrm{P}$ ficaram acumulados interna ou externamente nas raízes.

O peso seco da matéria seca total, das raízes e da parte aérea; os teores de fósforo na matéria seca da parte aérea e a eficiência na utilização de fósforo (PER), medida pela relação entre o peso seco da parte aérea e a quantidade de fósforo presente neste tecido seco de 25 plantas de cada um dos quatro cultivares de trigo estudados durante doze dias em soluções nutritivas contendo $0 ; 3,1 ; 6,2 ; 12,4$ e $31,0 \mathrm{mg} /$ litro de $P$, na ausência de alumínio, encontram-se no quadro $3 \mathrm{e}$, na presença de $3 \mathrm{mg} / \mathrm{litro}$ de $\mathrm{Al}{ }^{3+}$, no quadro 4 .

Segundo os dados obtidos, os cultivares IAC-21 e IAC-5 apresentaram, em todas as concentrações de fósforo, produções de matéria seca da parte aérea superiores ao. 'IAC-24' e 'Anahuac'. Os teores de $\mathrm{P}$ em porcentagem na matéria seca da parte aérea aumentaram para todos os cultivares à medida que as doses de $P$ das soluções foram aumentadas de 0 para $31,0 \mathrm{mg} / \mathrm{litro}$ de $P$.

Para o nivel de 3,1 mg/litro de $P$, 'Anahuac' mostrou o maior teor de $P$, corroborando com WHITEAKER et al. (1976), estudando feijão, e CAMARGO (1984), estudando trigo, cujos cultivares eficientes na utilizaçăo de fósforo apresentaram concentrações mais baixas de $P$ em relação aos ineficientes, considerando-se os baixos niveis desse nutriente nas soluçōes.

$\mathrm{Na}$ concentração de 3,1 mg/litro de $\mathrm{P}$, 'IAC-21' e 'IAC-5' apresentaram os maiores valores de PER.

Com base nos resultados e levando-se em consideração a produção de matéria seca, a proporção da eficiência na utilização de fósforo (PER), as respostas na produção de matéria seca da parte aérea, à medida que se aumentaram as concentraçōes de $P$, foi possivel diferenciar 'IAC-5' e. 'IAC-21' como eficientes na utilização de fósforo; 'IAC-24', como moderadamente eficiente, e 'Anahuac', como ineficiente.

Na presença de $3 \mathrm{mg} / \mathrm{litro}$ de $\mathrm{Al}^{3+}$ os cultivares $|\mathrm{AC}-21,| \mathrm{AC}-5$ e $\mid \mathrm{AC}-24$ apresentaram, em todas as concentrações de $P$, produções superiores de matéria seca da parte aérea em relação ao 'Anahuac'. Os teores de $P$ em porcentagem na matéria seca da parte aérea também aumentaram para os quatro cultivares, à medida que se elevaram os niveis de $P$ de 0 para $31,0 \mathrm{mg} / \mathrm{litro}$. Para $3,1 \mathrm{mg} / \mathrm{litro}$ de $\mathrm{P}, \mathrm{o}$ 'Anahuac' exibiu também o teor mais elevado de $\mathrm{P}$ e, o 'IAC-5', o menor. 


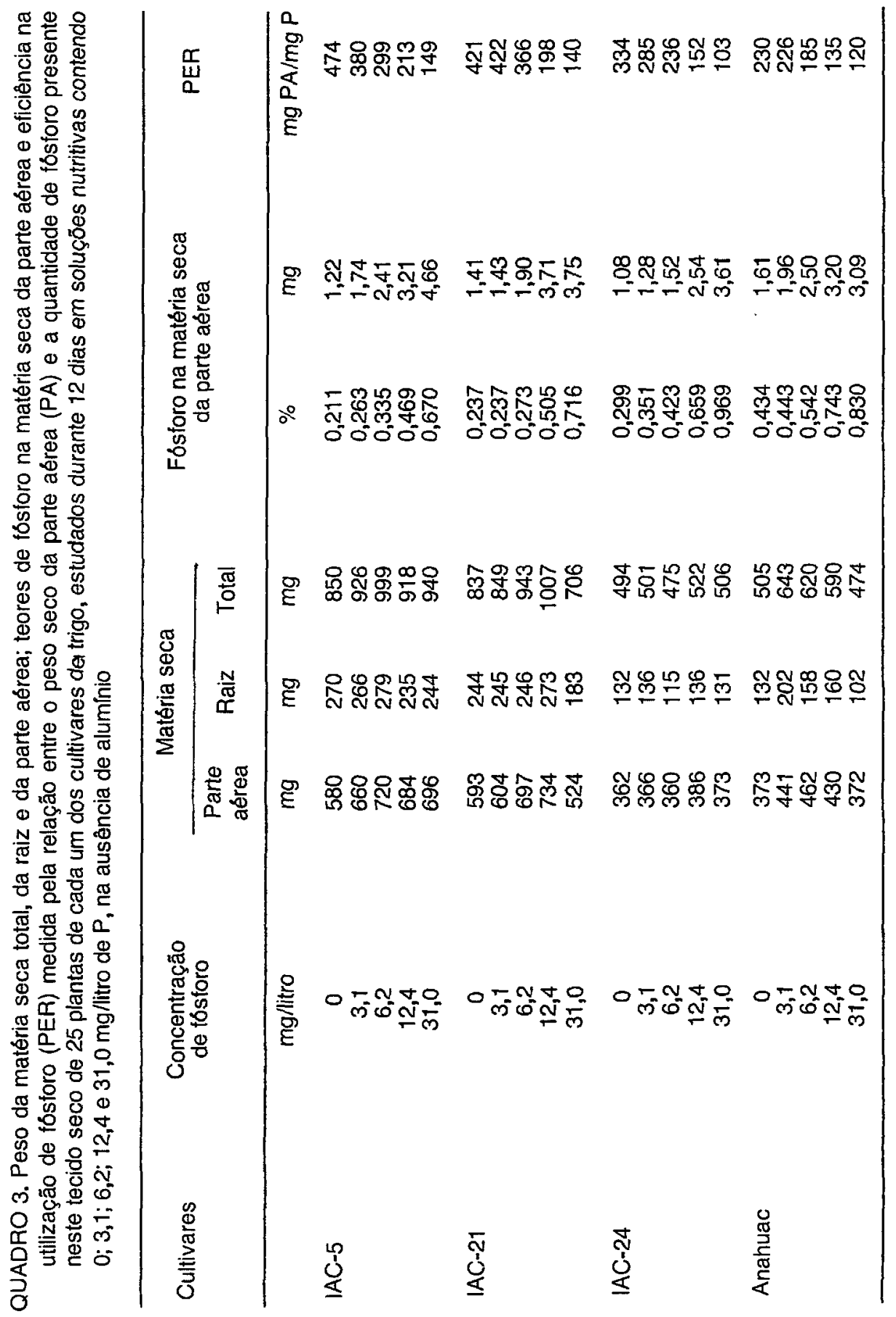




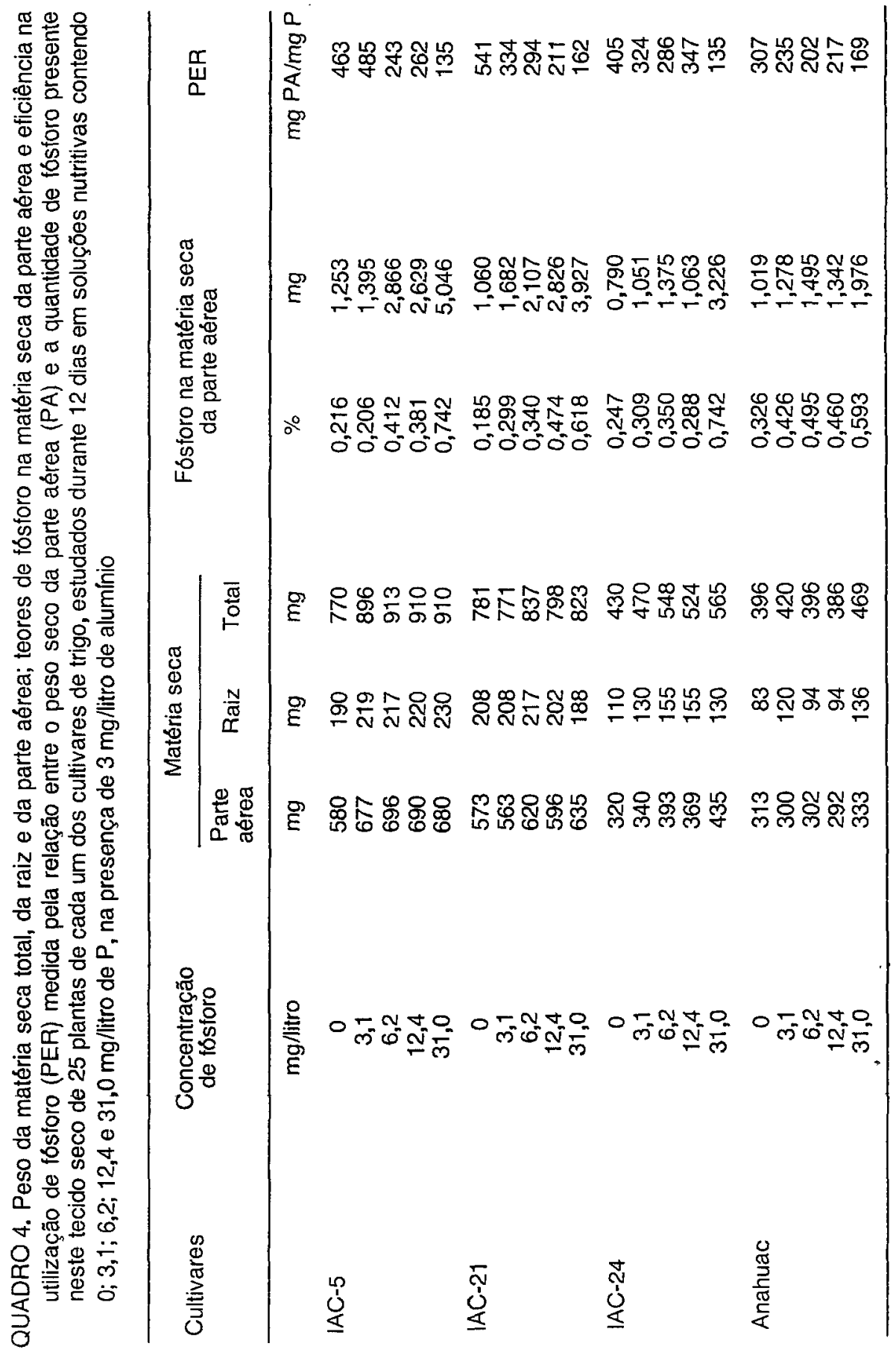


Este apresentou a maior proporção de eficiência na utilização de fósforo (PER) em relação aos demais, quando na adição de $3,1 \mathrm{mg} / \mathrm{litro}$ de $P$ combinado com 3 $\mathrm{mg} /$ litro de $\mathrm{Al}^{3+}$ nas soluções.

$O$ 'IAC-5' foi considerado eficiente na utilização de fósforo; 'IAC-21' e 'IAC-24', moderadamente eficientes, e 'Anahuac', ineficiente, levando-se em consideração a produção de matéria seca da parte aérea, a proporção de eficiência na utilização de fósforo (PER) no nivel de 3,1 mg/litro de P combinado com $3 \mathrm{mg} / \mathrm{litro}$ de $\mathrm{Al}^{3+}$ nas soluções, e as respostas na produção na matéria seca da parte aérea, à medida que se aumentaram as concentrações de $P$.

\section{CONCLUSÕES}

1) A técnica empregada para o estudo diferencial de cultivares de trigo, centeio e triticale, em relação à tolerância à toxicidade de alumínio, foi de utilidade, possibilitando a separação de cultivares tolerantes e sensiveis, empregando-se somente soluções de tratamento contendo diferentes niveis de $\mathrm{Al}^{3+}$, em um curto periodo de tempo.

2) Os cultivares de centeio, Branco, e de triticale, TCEP 77138 , mostraram a maior tolerância ao aluminio, levando-se em consideração o comprimento das raizes primárias centrais após doze dias de crescimento nas soluçōes de tratamento contendo $10 \mathrm{mg} /$ litro de $\mathrm{Al}^{3+}$, independente das concentrações de $\mathrm{P}$. Os de trigo, 'BH-1146', 'IAC-5', 'IAC-21' e 'IAC-24' apresentaram-se como tolerantes à toxicidade de aluminio, e o 'Anahuac', como sensivel, levando-se em consideração o crescimento das raízes primárias após doze dias de crescimento nas soluçōes de tratamento contendo $3 \mathrm{mg} /$ litro de $\mathrm{Al}^{3+}$, independendo das concentrações de $P$.

3) O sintoma de toxicidade de alumínio ficou acentuado para todos os cultivares, pelo aumento da concentraçāo de alumínio e fósforo nas soluçōes de tratamento.

4) Os cultivares de trigo IAC-5 e IAC-21 foram considerados eficientes na utilização de fósforo; o 'IAC-24', moderadamente eficiente, e o 'Anahuac', ineficiente para as soluções contendo $3,1 \mathrm{mg} /$ litro de $\mathrm{P}$ na ausência de $\mathrm{Al}^{3+}$. Nas soluções contendo $3,1 \mathrm{mg} /$ litro de $\mathrm{P}$, porém na presença de $3 \mathrm{mg} / \mathrm{litro}$ de $\mathrm{Al}^{3+}$, o 'IAC-5' foi considerado eficiente na utilização de $P$, 'IAC-21' e 'IAC-24', moderadamente eficientes e 'Anahuac', ineficiente, considerando a produção de matéria seca, a proporção de eficiência na utilização de fósforo e as respostas na produção de matéria seca da parte aérea, à medida que se aumentaram as concentrações de P nas soluções. 


\title{
SUMMARY
}

\section{EVALUATION OF WHEAT, TRITICALE AND RYE CULTIVARS FOR PHOSPHORUS EFFICIENCY AND TOLERANCE TO ALUMINUM TOXICITY IN NUTRIENT SOLUTION}

\begin{abstract}
Five wheat cultivars, one triticale and one rye cultivar were studied in aerated nutrient solution with one tenth of the salt concentration of a complete nutrient solution, $\mathrm{pH}=4.0$ with five levels of aluminum $(0,1,3,6$ and $10 \mathrm{mg} / \mathrm{l})$ combined with five levels of phosphorus $(0 ; 3.1 ; 6.2 ; 12.4$ and $31 \mathrm{mg} / \mathrm{l})$. As controls, it was used a complete nutrient solution and distilled water. The aluminum tolerance was evaluated by measuring the primary root lenght of the seedlings after a 12-days growth period in the different treatment solutions. The rye cultivar (Branco) and the triticale cultivar (TCEP 77138) were the most tolerant as far as aluminum toxicity is concerned, independently of the phosphorus concentrations into the solutions. The wheat cultivars: $\mathrm{BH}-1146,|\mathrm{AC}-5,| \mathrm{AC}-21$ and $\mid \mathrm{AC}-24$ exhibited Al tolerance in a lower degree when compared with rye and the triticale cultivar. Anahuac showed high sensitivity to aluminum toxicity. The wheat cultivars IAC-5 and IAC-21 were efficient in $\mathrm{P}$ utilization; IAC-24 was moderately efficient and Anahuac was considered an inefficient cultivar, taking into account the $P$ efficiency ratio (PER) calculated as $\mathrm{mg}$ of top dry weight yield per $\mathrm{mg}$ of $\mathrm{P}$ in the top tissue when nutrient solutions containing low levels of $P(3.1 \mathrm{mg} / \mathrm{l})$ in the absence of $\mathrm{Al}^{3+}$ were used. Considering the nutrient solutions containing $3.1 \mathrm{mg} / \mathrm{l}$ of $P$ combined with $3 \mathrm{mg} / \mathrm{l}$ of $A \mathrm{P}^{3+}$, the cultivar $\mathrm{IAC}-5$ was considered efficient in P utilization; 'IAC-21' and 'IAC-24', moderately efficient and 'Anahuac', inefficient.
\end{abstract}

Index terms: wheat, friticale, rye, cultivars; aluminum tolerance; phosphorus efficiency; phosphorus efficiency ratio; root lenght, top dry weight, nutrient solution.

\section{REFERÊNCIAS BIBLIOGRÁFICAS}

ALI, M.S. Influence of cations on aluminum toxicity in wheat (Triticum aestivum Vill, Host). Corvallis, Oregon State University, 1973. 102f. Tese (Doutoramento)

BATAGLIA, O.C.; TEIXEIRA, J.P.F.; FURLANI, P.R.; FURLANI, A.M.C. \& GALLO, J.R. Métodos de análise química de plantas. Campinas, Instituto Agronômico, 1978. 31p. (Circular, 87)

CAMARGO, C.E.O A concentração de fósforo na tolerância de cultivares de trigo à toxicidade de alumínio em soluçōes nutritivas. Bragantia, Campinas, 44(1):49-64, 1985.

- Efeito de diferentes niveis de fósforo em solução nutritiva e no solo no comportamento de cultivares de trigo. Bragantia, Campinas, 43(1):63-86, 1984.

\& FELÍCIO, J.C. Tolerância de cultivares de trigo, triticale e centeio em diferentes níveis de alumínio em solução nutritiva. Bragantia, Campinas, 43(1):9-16, 1984. 
CAMARGO, C.E.O. \& FREITAS, J.G. Tolerância de cultivares de trigo a diferentes niveis de ferro em soluçāo nutritiva. Bragantia, Campinas, 44(1):65-75, 1985.

\& OLIVEIRA, O.F. Tolerância de cultivares de trigo a diferentes níveis de alumínio em solução nutritiva e no solo. Bragantia, Campinas, 40:21-31, 1981.

CAMPBELL, L.G. \& LAFEVER, H.N. Correlation of field and nutrient culture techniques of screening wheat for aluminum tolerance. In:WORKSHOP ON PLANT ADAPTATION TO MINERAL STRESS IN PROBLEM SOILS, Beltsville, Maryland, 1976, edited by Madison, J. Wright - Proceedings. Ithaca, Cornell University, 1976. p.277-286.

FOY, C.D.; LAFEVER, H.N.; SCHWARTZ, J.W. \& FLEMING, A.L. Aluminum tolerance of wheat cultivars related to region of origin. Agronomy Journal, 66:751-758, 1974.

GABELMAN, W.H. Genetic potentials in nitrogen, phosphorus and potassium efficiency. In:WORKSHOP ON PLANT ADAPTATION TO MINERAL STRESS IN PROBLEM SOILS, Beltsville, Maryland, 1976, edited by Madison, J. Wright-Proceedings. Ithaca, Cornell University, 1976. p.205-212.

GERLOFF, G.C. Plant efficiencies in the use of nitrogen, phosphorus and potassium. In:WORKSHOP ON PLANT ADAPTATION TO MINERAL STRESS IN PROBLEM SOILS, Beltsville, Maryland, 1976, edited by Madison, J. Wright - Proceedings. Ithaca, Cornell University, 1976. p.161-173.

MOORE, D.P.; KRONSTAD, W.E. \& METZGER, R.J. Screening wheat for aluminum tolerance. In:WORKSHOP ON PLANT ADAPTATION TO MINERAL STRESS IN PROBLEM SOILS, Beltsville, Maryland, 1976, edited by Madison, J. Wright - Proceedings. Ithaca, Cornell University, 1976. p.287-295.

WHITEAKER, G.; GERLOFF, G.C.; GABELMAN, W.H. \& LINDGREN, D. Intraspecific differences in growth of beans at stress levels of phosphorus. Journal American Society for Horticultural Science, 101(4):472-475, 1976. 